\title{
A New Model for Harmonizing Scores Growth Among Multiple Criteria of Excellence Model of EFQM: A Case Study in Sepahan Industrial Group Co.
}

\author{
Reza Farzipoor Saen
}

Department of Industrial Management, Faculty of Management and Accounting, Islamic Azad University-Karaj Branch, Karaj, Iran, P. O. Box: 31485-313

Tel: 0098 (261) 4418144-6

Fax: 0098 (261) 4418156

E-mail: farzipour@yahoo.com

\begin{abstract}
The European Foundation for Quality Management (EFQM) excellence model has been used extensively and beneficially in manufacturing, banking and finance, education, management and consultancy, etc. However, EFQM may not have a strong sense of where to invest as a strategic priority, or where improvement will make the biggest impact in business performance and results. The objective of this paper is to develop a mathematical model for harmonizing the scores growth among 9 criteria of EFQM model subject to available time, available budget, preference of Decision Maker (DM), and precedence constraint. To harmonize the scores growth among multiple criteria, a goal programming model is developed.
\end{abstract}

Keywords: EFQM, Goal Programming, Harmonization.

\section{Introduction}

Increased global competition and improved communications have lead to greater customer expectation. The European Foundation for Quality Management (EFQM) excellence model has been used extensively and beneficially in manufacturing, banking and finance, education, management and consultancy, etc. Organisations apply the EFQM excellence model, since the pursuit of business excellence through Total Quality Management (TQM) is a decisive factor in allowing them to compete in today's global market. EFQM quickly became apparent that organisations were starting to use the excellence model as an internal diagnostic tool regardless of any plans for entering for the award and thus was born the process that has become known as selfassessment. 
The process of self-assessment is comprehensive, systematic and performed periodically, typically annually. Using self-assessment, an organisation can identify its own strengths and areas for improvement and compare its overall performance to widely accepted European levels of what constitutes "good practice”. As a result of the assessment, an organisation will have an indication as to where it may need to improve significantly, where it performs adequately and where it excels against the ideal benchmark. However, it may not have a strong sense of where to invest as a strategic priority, or where improvement will make the biggest impact in business performance and results (Lamotte and Carter, 2000).

Research in the area of EFQM planning is very limited. Here, some of them are introduced. Minkman et al. (2007) reviewed the literature on the Malcolm Baldrige Quality Award (MBQA) criteria, the EFQM Excellence model and the Chronic Care Model. The focus is on the empirical evidence for improved performance by the implementation of interventions based on these models. Ruiz-Carrillo and Fernandez-Ortiz (2005) discussed the usefulness of the EFQM model to identify the most representative resources and capabilities of the enterprise that allow to identify what part of its structure generates the key resources to create competitive advantages. Their work confirms the merits of the EFQM quality model as an effective tool to measure the basis of the competitive advantage of a given organization. To analyze EFQM, Calvo-Mora et al. (2005) applied Structural Equations Method and Partial Least Squares techniques. The results from the analysis of the measurement and structural model support the reliability and validity of the European Excellence Model as a reference framework for the implementation, evaluation and improvement of quality in the area of higher education. Zerafat Angiz Langroudi et al. (2008) studied some of the weaknesses of the EFQM model. Then, with the usage of structure of input-output governing of the model and using of Data Envelopment Analysis (DEA), a method was offered to recognize the lack of the proportion between enablers and the results of organization which may occur due to problems and obstacles hidden in the heart of organization. Bou-Liusar et al. (2009) analyzed the extent to which the EFQM Excellence Model captures the main assumptions involved in the TQM concept, that is, the distinction between technical and social TQM issues, the holistic interpretation of TQM in the firm, and the causal linkage between TQM procedures and organizational performance. Based on responses collected from managers of 446 Spanish companies by means of a structured questionnaire, they found that: (a) social and technical dimensions are embedded in the model; (b) both dimensions are intercorrelated; (c) they jointly enhance results. These findings support the EFQM Excellence Model as an operational framework for TQM, and also reinforce the results obtained in previous studies for the MBQA, suggesting that quality award models really are TQM frameworks. 
The objective of this paper is to develop a mathematical model for harmonizing the scores growth among 9 criteria of EFQM model subject to available time, available budget, preference of Decision Maker (DM), and precedence among criteria.

To harmonize EFQM score growth among 9 criteria, time, budget, precedence of criteria, and preference of DM should be considered. Recently, Farzipoor Saen (2005) developed a mathematical model for harmonizing the scores growth among 9 criteria of EFQM model with respect to constraints of time, budget, and preference of DM. However, he did not consider the precedence constraint among criteria. The approach presented in this paper has some distinctive features.

- A unique mathematical model for harmonizing the scores growth among criteria of EFQM model subject to constraints such as available time, available budget, precedence of criteria, and preference of DM is developed.

- Precedence constraint among criteria is considered for the first time.

- An application of the methodology has been performed.

This paper proceeds as follows. In section 2, a brief review of EFQM excellence model is presented. In section 3, the mathematical model is developed. A numerical example is given in section 4. Finally, concluding remarks are explained in section 5.

\section{The EFQM Excellence Model}

The EFQM excellence model consists of 9 criteria. The five criteria on the left-hand side of Fig. 1 are called factors (enablers) and are concerned with how the organisation performs various activities. The four criteria on the right of Fig. 1 are concerned with the results the organisation is achieving with respect to different stakeholders (Watson, 2002). EFQM excellence model assumes that excellent results with respect to key performance, client result, personnel result and community result are achieved through leadership driving policy and strategy, personnel, partnership resources, and process. The model is based on the assumption that: the satisfaction of the customers, the employees and a positive impact on society can be achieved by means of political and strategic leadership, a right employees management, an effective use of the resources available and an adequate definition of the processes, which finally would lead to excellence in the results. The meaning of each criterion is summarized in Table 1. 
Table 1. The EFQM Excellence Model criteria

\begin{tabular}{|c|c|}
\hline Criterion & Definition \\
\hline Leadership & $\begin{array}{l}\text { Excellent leaders develop and facilitate the achievement of the mission and } \\
\text { vision. They develop organizational values and systems required for sustainable } \\
\text { success and implement these via their actions and behaviors }\end{array}$ \\
\hline Policy and & Excellent organizations implement their mission and vision by developing a \\
\hline Strategy & $\begin{array}{l}\text { stakeholder focused strategy that takes account of the market and sector in which } \\
\text { it operates. Policies, plans, objectives and processes are developed and deployed } \\
\text { to deliver strategy }\end{array}$ \\
\hline People & $\begin{array}{l}\text { Excellent organizations manage, develop and release the full potential of their } \\
\text { people at an individual, team-based and organizational level. They promote } \\
\text { fairness and equality and involve and empower their people }\end{array}$ \\
\hline $\begin{array}{l}\text { Partnerships } \\
\text { and resources }\end{array}$ & $\begin{array}{l}\text { Excellent organizations plan to manage external partnerships, suppliers and } \\
\text { internal resources in order to support policy and strategy and the effective } \\
\text { operation of processes }\end{array}$ \\
\hline Processes & $\begin{array}{l}\text { Excellent organizations design, manage and improve processes in order to fully } \\
\text { satisfy, and generate increasing value for, customers and other stakeholders }\end{array}$ \\
\hline Client results & $\begin{array}{l}\text { Excellent organizations comprehensively measure and achieve outstanding } \\
\text { results with respect to their clients }\end{array}$ \\
\hline People results & $\begin{array}{l}\text { Excellent organizations comprehensively measure and achieve outstanding } \\
\text { results with respect to their people }\end{array}$ \\
\hline Society results & $\begin{array}{l}\text { Excellent organizations comprehensively measure and achieve outstanding } \\
\text { results with respect to society }\end{array}$ \\
\hline $\begin{array}{l}\text { Key } \\
\text { performance } \\
\text { results }\end{array}$ & $\begin{array}{l}\text { Excellent organizations comprehensively measure and achieve outstanding } \\
\text { results with respect to the key element of their policy and strategy }\end{array}$ \\
\hline
\end{tabular}

Source: adapted from Bou-Liusar et al. (2009)

According to the EFQM Model, improvement in the scores of enabler criteria results the high scores of result criteria. In other words, the enablers are precedence for the results.

A certain number of weights are assigned to each of the nine criteria of the model, reflecting their relative importance to the achievement of excellence. The model is split 50-50 between enablers and results. Through a self-assessment process, organisations are required to assess the excellence of the approach used and the extent of the deployment of each approach at all levels. The method of evaluation - called RADAR - is central to the model, consisting of five elements: results, approach, deployment, assessment and review. The five steps of the RADAR are a modification of the plan-do-check-act cycle as developed by Deming (Moeller et al., 2000). 


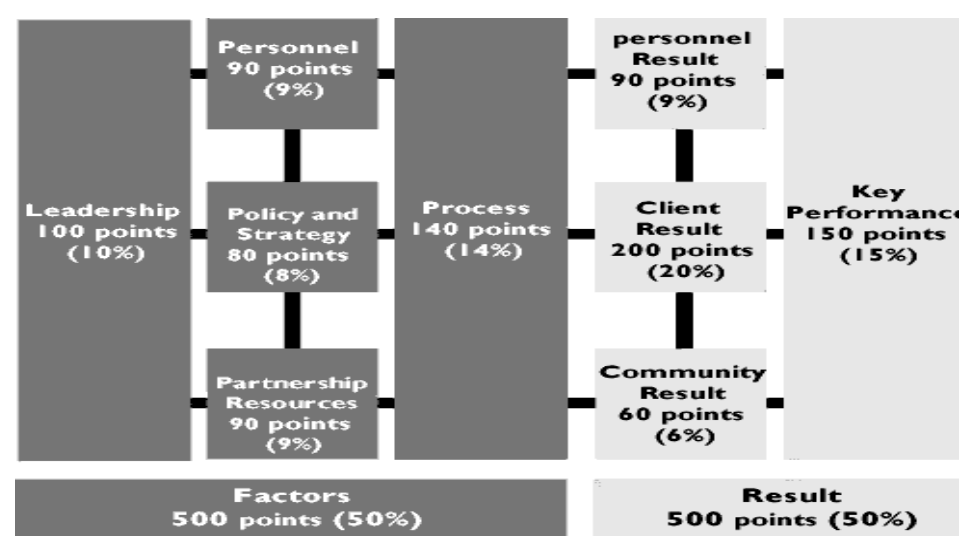

Fig. 1 EFQM Excellence Model.

\section{Proposed Model}

Goal programming (GP) is one of the most powerful, multiobjective decision making approaches in practical decision making problems. Since the intention is to harmonize all the 9 objectives (criteria), therefore there is not any priorities among criteria (Arikan and Gungor, 2001).

After determining the points of organization by EFQM model, to harmonize the scores growth among multiple criteria, a mathematical model is developed. Note that by "score” we mean assessment outcome without considering predetermined weights, and by "point" we mean assessment outcome after multiplying by predetermined weights in related scores.

The generic maxmin optimization problem

$$
\max _{x} \min _{h} f_{h}(x) ; \quad h=1, \ldots, m
$$

is transformed into the following equivalent optimization problem

$$
\begin{array}{ll}
\max _{x} \quad z \\
\text { s.t. } \\
& f_{h}(x) \geq z ; \quad h=1, \ldots, m
\end{array}
$$

It is noted parenthetically that

$$
z=\min _{h} f_{h}(x) ; \quad h=1, \ldots, m
$$

Based on these cases, and using the above transformation to develop a more explicit representation of the above problem, the optimization statement becomes as below. 
As mentioned before, there are constraints such as time, budget, DM preference, and precedence among criteria. Following model considers these constraints:

$\operatorname{Max} \quad$ Z

s.t.

$$
\begin{aligned}
& \frac{1}{w_{i}} x_{i} \geq z, \quad \quad i \in i_{r} \cup i_{e} \\
& \sum_{i \in i_{r} \cup i_{e}} w_{i} x_{i}=p, \quad(2) \\
& x_{i} \leq 100-l_{i}, \quad \quad \quad i \in i_{r} \cup i_{e} \\
& a_{i} x_{i} \leq t \quad\left(5 \in i_{r} \cup i_{e} \quad(4)\right. \\
& \sum_{i \in i_{r} \cup i_{e}} g_{i} x_{i} \leq b \quad(6) \\
& \sum_{i_{r}=6}^{9} x_{i_{r}} \leq \sum_{i_{e}=1}^{5} x_{i_{e}} \\
& x_{i} \geq 0, \quad i \in i_{r} \cup i_{e} \\
& z \geq 0 \quad(8)
\end{aligned}
$$

\subsection{Notations}

Z. slack variable for harmonizing scores among multiple criteria

$i_{e}=1,2, \ldots, 5$; number of enabler criteria

$i_{r}=6, \ldots, 9$; number of result criteria

$x_{i}$ : the score in the $i$ th criterion of EFQM that should be grown

$w_{i}$ : predetermined weight of the $i$ th criterion defined by EFQM

$p$ : difference between preferred point of DM and obtained current point

$l_{i}$ : obtained score in the $i$ th criterion

t. available time (days)

$b$ : available budget (dollars)

$a_{i}$ : required time of score growth by growing one unit of the $i$ th criterion

$g_{i}$ : required budget of score growth by growing one unit of the $i$ th criterion

In (1), the $w_{i}$ has been inverted. The main idea behind inversion is as follows. The criterion that has greater weight should be considered more important. Consequently, it must be in the first 
priority for score growth. In (2), preference of DM is considered. The difference between maximum score for each criterion (100 is the maximum score in each criterion) and $l_{i}$, creates an upper bound for score growth of th criterion that has been denoted in (3). Inequalities (4) and (5) define available time and budget constraints, respectively. Inequality (6) implies that enabler criteria are precedence for the result criteria. Finally, (7) and (8) are non-negativity conditions.

In the next section a numerical example is presented.

\section{Numerical Example}

Sepahan Industrial Group Co. (SIG), was established in 1973 for manufacturing steel tubes, pipes and profiles in Iran. Nowadays after over 30 years, SIG has become a major and pioneer manufacturer and exporter of different kinds of steel pipes, tubes and profiles in Iran as well as the middle-east. SIG production plants with more than 880 employees and annual production capacity of more than 420,000 metric tons at a total area of more than 1,000,000 square meters are located near the historical city of Isfahan at the central part of Iran. In 2008, SIG was assessed based on EFQM model. The scores in tems of criteria have been represented in Table 2. Total point equals with 321.82.

Table 2. The Points

\begin{tabular}{|c|l|c|c|c|}
\hline Row & Criterion & Score $\left(\boldsymbol{I}_{\boldsymbol{i}}\right)$ & Predeter mined Weight $\left(\boldsymbol{w}_{\boldsymbol{i}}\right)$ & Point \\
\hline 1 & Leadership & 35.3 & 1 & 35.3 \\
\hline 2 & Policy and strategy & 28.9 & .8 & 23.12 \\
\hline 3 & Personnel & 38.1 & .9 & 34.29 \\
\hline 4 & Partnership and resources & 39.7 & .9 & 35.73 \\
\hline 5 & Process & 37.3 & 1.4 & 52.22 \\
\hline 6 & Client result & 22.7 & 2 & 45.4 \\
\hline 7 & Personnel result & 25.2 & .9 & 22.68 \\
\hline 8 & Community result & 28.8 & .6 & 17.28 \\
\hline 9 & Key performance & 37.2 & 1.5 & 55.8 \\
\hline & & & Summation & 321.82 \\
\hline
\end{tabular}

Moreover, preference of DM, in addition to points 321.82, is to increase total points to 60 in the next year (i.e. 381.82 points). The DM intends to have a plan so that the score growth harmony among multiple criteria is guaranteed. 
There are 220 working days available for growing scores in the next year. Table 3 shows required time for each score growth of the ith criterion. Also, available budget for improvement is 800000000 Rials. Table 4 presents required budget for each score growth of the $t$ th criterion.

Table 3. Required time for each score growth of the $i$ th Criterion

\begin{tabular}{|c|c|c|}
\hline Row & Criterion & Required time (days) \\
\hline 1 & Leadership & 40 \\
\hline 2 & Policy and strategy & 50 \\
\hline 3 & Personnel & 50 \\
\hline 4 & Partnership resources & 40 \\
\hline 5 & Process & 40 \\
\hline 6 & Client result & 40 \\
\hline 7 & Personnel result & 25 \\
\hline 8 & Community result & 50 \\
\hline 9 & Key performance & 20 \\
\hline
\end{tabular}

Table 4. Required budget for each score growth of the ith criterion

\begin{tabular}{|c|l|c|}
\hline Row & Criterion & Required budget (Rials) \\
\hline 1 & Leadership & 2000000 \\
\hline 2 & Policy and strategy & 5000000 \\
\hline 3 & Personnel & 25000000 \\
\hline 4 & Partnership resources & 25000000 \\
\hline 5 & Process & 20000000 \\
\hline 6 & Client result & 3000000 \\
\hline 7 & Personnel result & 6000000 \\
\hline 8 & Community result & 5000000 \\
\hline 9 & Key performance & 25000000 \\
\hline
\end{tabular}

Applying the proposed model, the results have been shown in Table 5. Based on the "score growth value" column in Table 5, if these values are multiplied by the predetermined weights, the summation will be point 60 .

Table 5, reports the next year plan. By implementing this plan, harmony among multiple criteria of EFQM is guaranteed. As a result, total point will be 381.82 (i.e. 321.82+60). 
Table 5. Computations results

\begin{tabular}{|c|l|c|c|c|}
\hline Row & Criterion & Score growth value & Predeter mined Weight & Point \\
\hline 1 & Leadership & 5.5 & 1 & 5.5 \\
\hline 2 & Policy and strategy & 4.4 & .8 & 3.52 \\
\hline 3 & Personnel & 4.4 & .9 & 3.96 \\
\hline 4 & Partnership resources & 5.5 & .9 & 4.95 \\
\hline 5 & Process & 5.5 & 1.4 & 7.7 \\
\hline 6 & Client result & 5.5 & .9 & 11 \\
\hline 7 & Personnel result & 8.08 & .6 & 7.272 \\
\hline 8 & Community result & 1.65 & 1.5 & .99 \\
\hline 9 & Key performance & 10.07 & Summation & 60 \\
\hline
\end{tabular}

\section{Concluding Remarks}

The EFQM Model is a non-prescriptive framework, which recognizes that excellence may be achieved in a sustainable manner through the adoption of different approaches. Within this framework, there are certain fundamental concepts that are expressed and specified in nine dimensions or criteria, which serve as a guide for implementing TQM, and for measuring the results that are being achieved by the organization. However, EFQM does not recommend where to invest as a strategic priority.

In this paper a method for harmonizing scores growth among multiple criteria of EFQM excellence model was proposed. Employing the proposed method, practical difficulties for harmonizing nine criteria of scores growth are largely reduced. The proposed model is a useful tool that serves as a stimulus to guide organizations towards scores growth of EFQM, so that the harmony among the criteria is garaunteed.

However, determining the required time and budget for growing of each criterion, is a difficult task and needs accurate attention of DM.

The problem considered in this research is at initial stage of investigation and further studies can be done based on the results of this paper. One of them is as below:

This paper assumed that the parameters are crisp. However, a mathematical model is needed in the presence of fuzzy data. 


\section{Acknowledgement}

The author wishes to thank two anonymous referee for the valuable suggestions and comments.

\section{References}

Arikan, F. and Gungor, S. (2001) 'An application of fuzzy goal programming to a multiobjective project network problem', Fuzzy Sets and Systems, Vol. 119, No. 1, pp. 49-58.

Bou-Liusar, J. C., Escrig-Tena, A. B., Roca-Puig, V. and Beltran-Martin, I. (2009) 'An empirical assessment of the EFQM excellence model: evaluation as a TQM framework relative to the MBNQA model', Journal of Operations Management, Vol. 27, No. 1, pp. 1-22.

Calvo-Mora, A., Leal, A. and Roldan, J. L. (2005) 'Relationships between the EFQM model criteria: a study in Spanish universities’, Total Quality Management, Vol. 16, No. 6, pp. 741-770.

Farzipoor Saen, R. (2005) 'Harmonizing scores growth among multiple criteria of excellence model of EFQM by goal programming technique', Proceedings of International Conference on Numerical Analysis and Applied Mathematics (ICNAAM 2005), Greece, pp. 183-185.

Lamotte, G. and Carter, G. (2000) 'Are the balanced scorecard and the EFQM excellence model mutually exclusive or do they work together to bring added value to a company?' (Working Paper).

Minkman, M., Ahaus, K. and Huijsman, R. (2007) 'Performance improvement based on integrated quality management models: what evidence do we have? a systematic literature review', International Journal for Quality in Health Care, Vol. 19, No. 2, pp. 90-104.

Moeller, J., Breinlinger O’ Reilly, J. and Elser, J. (2000) 'Quality management in German health care - the EFQM excellence model', International Journal of Health Care Quality Assurance, Vol. 13, No. 6, pp. 254-258.

Ruiz-Carrillo, J. I. C. and Fernandez-Ortiz, R. (2005) 'Theoretical foundation of the EFQM model: the resource-based view', Total Quality Management, Vol. 16, No. 1, pp. 31-55. 
Zerafat Angiz Langroudi, M., Jandaghi, G. and Ben Mustafa, A. (2008) 'Validity examination of EFQM’s results by DEA models', Journal of Applied Quantitative Methods, Vol. 3, No. 3, pp. 1728.

Watson, P. (2002) 'Implementing the European foundation for quality management excellence model', FIG XXII International Congress Washington, D.C. USA, pp. 19-26. 